\title{
Article
}

\section{Environmental chemical stressors as epigenome modifiersta new horizon in assessment of toxicological effects}

Shen, Heqing, Martin, Francis L and Su, Yanhua

Available at http://clok.uclan.ac.uk/16270/

Shen, Heqing, Martin, Francis L ORCID: 0000-0001-8562-4944 and Su, Yanhua (2014) Environmental chemical stressors as epigenome modifiers:a new horizon in assessment of toxicological effects. Chinese Science Bulletin, 59 (4). pp. 349-355. ISSN 1001-6538

It is advisable to refer to the publisher's version if you intend to cite from the work. http://dx.doi.org/10.1007/s11434-013-0007-6

For more information about UCLan's research in this area go to http://www.uclan.ac.uk/researchgroups/ and search for < name of research Group>.

For information about Research generally at UCLan please go to http://www.uclan.ac.uk/research/

All outputs in CLoK are protected by Intellectual Property Rights law, including Copyright law. Copyright, IPR and Moral Rights for the works on this site are retained by the individual authors and/or other copyright owners. Terms and conditions for use of this material are defined in the policies page.

\section{CLoK}

Central Lancashire online Knowledge www.clok.uclan.ac.uk

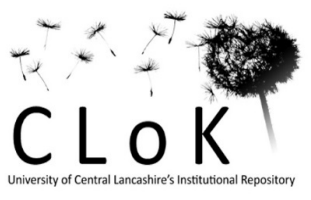




\title{
Environmental chemical stressors as epigenome modifiers: a new horizon in assessment of toxicological effects
}

\author{
Heqing Shen $\cdot$ F. L. Martin $\cdot$ Yanhua Su
}

Received: 7 February 2013/Accepted: 9 April 2013/Published online: 31 December 2013

(C) Science China Press and Springer-Verlag Berlin Heidelberg 2013

\begin{abstract}
In eukaryotic cells, chromatin transformation from euchromatin into heterochromatin as a means of controlling gene expression and replication has been known as the "accessibility hypothesis". The interplay of epigenetic changes including histone modifications, DNA methylation, RNA interference (RNAi) and other functional epigenetic components are intricate. It is believed that these changes are well-programmed, inherited and can be modified by environmental contaminant stressors. Environmentally-driven epigenetic alterations during development, e.g. embryonic, foetal or neonatal stage, may influence disease susceptibility in adulthood. Therefore, understanding how epigenome modifications develop in response to environmental chemicals and, how epigeneticxenobiotic interactions influence human health will shed new insights into gene-environment interactions in the epidemiology of several diseases including cancer. In this review, we consider studies of chemical modifiers including nutritional and xenobiotic effects on epigenetic components in vitro or in vivo. By examining the most-studied
\end{abstract}

Electronic supplementary material The online version of this article (doi:10.1007/s11434-013-0007-6) contains supplementary material, which is available to authorized users.

\section{H. Shen $(\bowtie)$}

Key Laboratory of Urban Environment and Health, Institute of Urban Environment, Chinese Academy of Sciences,

Xiamen 361021, China

e-mail: hqshen@iue.ac.cn

\section{F. L. Martin}

Centre for Biophotonics, Lancaster Environment Centre,

Lancaster University, Lancashire LA1 4YQ, UK

\section{Y. Su}

Department of Preventive Medicine, School of Public Health of Xiamen University, Xiamen 361005, China epigenome modifications and how their respective roles are interlinked, we highlight the central role of xenbioticmodified epigenetic mechanisms. A major requirement will be to study and understand effects following environmentally-relevant exposures. We suggest that the study of epigenetic toxicology will open up new opportunities to devise strategies for the prevention or treatment of at-risk populations.

Keywords DNA methylation - Epigenetics · Environmental stressor - Epigenetic toxicology · Histone modifications · Noncoding RNA (ncRNA)

In eukaryotic cells, chromatin transformation from euchromatin into heterochromatin as a means of controlling gene expression and replication has been known as the "accessibility hypothesis". Various epigenome modifications can remodel chromatin accessibility [1,2]. Within the cell nucleus, the most actively transcribed chromatin is lightly-packed euchromatin, which is characteristically hyperacetylated at $\mathrm{N}$-terminal lysine residues in core Histones $\mathrm{H} 3$ (H3Kac; i.e. H3 lysine-9/14 acetylation) and H4 (H4Kac; i.e. Histone H4 acetylated lysine) along with hypomethylated $\mathrm{CpG}$ islands in related gene promoter regions. Some constitutive euchromatin may be "always turned on", including regions encoding housekeeping genes. Rendering it inaccessible, tightly-packed heterochromatin usually expresses different variations of hypoacetylated histones ranging between the two extreme levels representing constitutive and facultative. Constitutive heterochromatin is poorly expressed and consists mainly of repetitive structures such as (peri) centromeric satellites and telomeric repeats with typically tri-methylated lysine residues $\mathrm{H} 3 \mathrm{~K} 9$ (H3K9me3; i.e. Histone $\mathrm{H} 3$ trimethyl 
Lysine 9), in which the histone methyltransferases (HMTs) and heterochromatin protein 1 (HP1) are specifically bound to H3K9me3 [3-5].

For some genes subject to developmental regulation, sequences may be either tightly packaged in facultative heterochromatin containing hypermethylated $\mathrm{CpG}$ islands in one cell whilst in another, they may occur in euchromatin with hypomethylated $\mathrm{CpG}$ islands; this could include the $\mathrm{X}$ chromosome genes that are inactive in female mammals but active in males and the inactive alleles of methylated genes with monoallelic expression subject to imprinting [6]. In facultative heterochromatin, H3K9 (i.e. Histone H3 Lysine 9) and H4K20 (i.e. Histone H4 Lysine 20) are in general di- or mono-methylated; the silenced gene is maintained by H3K27me3 (i.e. Histone $\mathrm{H} 3$ trimethyl Lysine 27) and mono-ubiquitylated H2AK119 [5]. Histone modifications also include phosphorylation, ubiquitinylation, sumoylation, ADP-ribosylation, carbonylation, deimination and proline isomerization [7].

In addition, chromatin architecture is regulated by ncRNAs; microRNAs (miRNAs) often act in concert with various components of the cell's chromatin and DNA methylation machinery to achieve stable silencing via the RNAi pathway, with associated alterations to chromatin structure [8]; these are believed to regulate up to one-third of all human genes by interfering with mRNA functions [9]. Heterochromatin formation appears to be broadly regulated by small RNAs, i.e. RNAi-related processes [8]. Several additional classes of ncRNAs, such as repeatassociated small-interfering (si) RNAs (RasiRNAs) in Drosophila and their mammalian counterparts Piwi protein-interacting RNAs (piRNAs), are found to be involved in the regulation of genomic architecture, the maintenance of germline genomic integrity and the ageing process [7, 8]. Moreover, as parental imprinting is intimately linked to ncRNAs [8], this reflects the fact that RNA-directed regulatory processes may also transfer epigenetic information not only within cells but also between cells and organ systems, as well as being trans-generational [10]. Recent research suggests LINE-1 retrotransposon RNA is an essential structural and functional epigenetic component for centromeric activity [11] and non-coding genes Xist (Xinactive specific transcript), an RNA gene on the X chromosome of placental mammals that acts as an effector of the X-inactivation process, can regulate the expansion of heterochromatin [12].

Although cross-talk with constitutive processes is a major epigenomic regulator [13-16], one also needs to consider the role that chemical modifiers, including nutritional and xenobiotic, play in modifying epigenetic components in vitro or in vivo. The core focus of this review will be on how xenobiotics-induced adverse epigenetic alterations or epigenetic toxicity beyond the DNA sequence impacts on heritable gene expression or phenotype.

\section{Chemical-induced epigenetic component alterations}

Whilst one inherits their genetic sequence code, the expression or silencing of individual genes can be modified by environmental factors [10,17]. Recent research suggests that exposure to environmental stressors, including nutritional factors and chemical or physical pollutants can alter gene expression via altered epigenetic components [1822]. Such epigenetic processes play a significant role in acclimation to environmental stresses. A wide range of environmental factors, including xenobiotic chemicals, diet, stress, behaviour, geographic location and even weather patterns have been shown to alter gene expression via epigenetic alterations [20, 21, 23]. Certain environmental stressor-stimulated epigenetic alterations can be passed from one generation to the future generations [24, 25]; however, these findings need to be robustly tested in future studies.

\subsection{Inorganic chemicals}

Acetylation has been linked with transcriptional stimulation [3]. Recent studies have associated nickel with histone modifications and altered chromatin organization. At nontoxic levels, it induces decreases of Histone $\mathrm{H} 4$ acetylation in yeast [26]. Post-nickel exposure, decreased gene expression coincided with three major histone modifications, including loss of acetylation (of H2A, H2B, H3 and $\mathrm{H} 4)$, increased H3K9me2 (i.e. Histone H3 dimethyl Lysine 9), and increased ubiquitinylation of $\mathrm{H} 2 \mathrm{~A}$ and $\mathrm{H} 2 \mathrm{~B}$ [2729]. Chromium exposure was linked to epigenetic-controlled gene expression alterations via interactions with histone acetyltransferases (HATs) and histone deacetylases (HDACs) [30], the enzymes that catalyze histone deacetylation and acetylation, respectively. Chromium reduces phosphorylation and trimethylation in $\mathrm{H} 3$, modifies a variety of acetylation marks in $\mathrm{H} 3$ and $\mathrm{H} 4$, and influences P16 hypermethylation in lung cancer tissues [30-32]. Developmental mouse exposure to low levels of methylmercury may induce epigenetic suppression via DNA hypermethylation of gene expression particularly of the brainderived neurotrophic factor (BDNF) promoter region in the hippocampus, an increase in histone H3K27me3 (i.e. Histone $\mathrm{H} 3$ trimethyl Lysine 27) and a decrease in H3ac (i.e. acetylated Histone H3) at the promoter IV [33].

Occupational or environmental exposure to cadmium, arsenic, nickel, chromium, methylmercury or lead can result in altered DNA methylation [21]; following heavy metal (cadmium, arsenic or nickel) exposures, the resulting 
pathologies in rodents exhibit an epigenetic profile that resembles that of animals fed a methyl-deficient diet. Short-term cadmium exposure inhibits DNA methyltransferases (DNMT) activity, but prolonged exposure increases DNA methylation and DNMT activity, resulting in neoplastic transformation in rat hepatocytes [34, 35]. Cadmium alterations of DNA methylation may be responsible for its carcinogenic properties. By promoter hypermethylation in human lung adenocarcinoma, plutonium can target P16 for inactivation [36]. Arsenic is also associated with gene-specific hypermethylation as well as global DNA hypomethylation, which depletes SAM ( $S$-adenosyl methionine) and represses DNMT1 and DNMT3A activity [37]. Adult mice exposed to sodium arsenite exhibit reduced DNA methylation whilst co-exposure of sodium arsenite with a methyl-deficient diet results in gene-specific hypomethylation in the promoter region of the oncogene Ha-ras [38]. An India-based human study showed a doseresponse relationship between hypermethylation and arsenic exposure from drinking water [39]. Similarly, a dose-dependent hypermethylation in blood DNA was associated with chronic arsenic exposure in Bangladeshi adults [40].

\subsection{Organic chemicals}

Exposure to some endocrine disruptors has been linked with epigenetic alterations that are inherited trans-generationally $[24,25]$ via germ line transmission of imprinted genes exhibiting an altered methylation pattern. Transient exposure to the oestrogenic insecticide methoxychlor and the antiandrogenic fungicide vinclozolin at the time of sex determination appeared to alter methylation of two imprinted genes of LPLase and cytokine-inducible SH2 protein in the male germ line of pregnant rats [24]. Adverse effects were reported to last for four subsequent generations in approximately $90 \%$ of males and, suggested vinclozolin-induced DNA methylation changes are inherited [41]. Vinclozolin may also target Sertoli cells in mice, and exploit miRNAs to elicit its anti-androgenic effects [42]. The oestrogenic diethylstilbestrol (DES) caused the aberrant DNA methylation of oestrogen-regulated genes such as lactoferrin $(L F)$ in mice exposed in utero or perinatally and transgenerational effects were observed in DES-exposed individuals [43-45]. Neonatal exposure to oestradiol and environmental levels of bisphenol A (BPA) resulted in multiple changes in cell signalling gene-specific DNA methylation patterns in rat prostate [46]. Exposure to BPA during early development was found to decrease agouti gene methylation. When pregnant yellow agouti mothers were fed BPA, yellower and unhealthier offspring compared to those on control diets were born. However, pregnant yellow mice administered BPA but kept on a methyl-rich diet had offspring that were predominantly brown [47]. Nonylphenol-treated cell lines (MCF-7 and HepG2 cells) exhibited altered miRNA profiles of let-7c, miR-16, -195, -200b, 200c, 205, -589, which are related to metabolism, immune responses, apoptosis, and cell differentiation [48]. Pre-implantation exposure of mice embryos to 2,3,7,8-tetrachlorodibenzo- $p$-dioxin (TCDD) resulted in altered methylation status of imprinted genes $H 19$ and IGF2 (insulin-like growth factor 2) [49]. Other endocrine disruptors including phthalates, polychlorinated biphenyls (PCBs) and organochlorine pesticides may also affect the reproductive system or induce tumour development by altering DNA methylation [50-53].

Many other chemical stressors can alter epigenetic markers. Exposure to oxidative stressor-like $\mathrm{H}_{2} \mathrm{O}_{2}$ increased HAT activity, which promoted acetylation and induced chromatin remodelling in alveolar epithelial cells [54]. Nucleoside analogues such as azacitidine that are incorporated into replicating DNA, inhibit methylation and reactivate previously-silenced genes [55]. The antisense oligonucleotide drug MG98 that down-regulates DNMT1 showed promise in phase I clinical trials [56]. Similarly, small molecules such as valproic acid that down-regulate HDACs are being used to induce growth arrest and tumour cell death [57]. Pogribny et al. [58] found Fisher 344 rat exposure to tamoxifen, a potent hepatocarcinogen in rats, leads to a significant up-regulation of known oncogenic miRNAs, such as the 17-92 cluster, miR-106a, and miR-34.

\subsection{Lifestyle-related and nutritional chemicals}

Polyphenols such as genistein, catechins and bioflavonoids in green tea can inhibit DNMTs and further inhibit methylation of candidate genes [59-63]; the pathways by which these chemicals affect DNA methylation remain obscure [60, 62, 64]. When a woman is exposed during pregnancy to polycyclic aromatic hydrocarbons (PAHs) from tobacco smoke, methylation of specific genes in the developing foetus is affected, and this is associated with a fourfold increase in asthma symptoms in children $<5$ years [65]. Exposure to airborne PAHs during pregnancy resulted in methylation of ACSL3 (expressed in lung and thymus tissue) with associated parental reporting of increased prevalence of child's asthma $<5$ years age; $73 \%$ of children with asthma exhibited ACSL3 methylation compared to $41 \%$ who were asymptomatic [66]. Cigarette smoking can also stimulate the demethylation of metastatic genes [67] and aberrant promoter hypermethylation of death-related protein kinase genes [67] in lung cancer, and downregulate miRNA expression in the lungs of rats [68]. A detrimental effect on the physical and mental development of offspring due to paternal chronic alcohol consumption, even in the absence of in utero 
alcohol exposure, was suggested to be the result of incorrect $H 19$ methylation and intergenic differentiallymethylated region (IG-DMR) [69]. Cocaine abuse may lead to histone acetylation and activation of genes, altering locomotor and rewarding responses to the drug [70]. Long-term $\mathrm{PM}_{10}$ exposure was inversely associated with methylation in both $A l u$ and LINE-1 (long interspersed nuclear element 1) [71]. Jardim et al. [72] found disruption of miRNA expression in human airway cells by diesel exhaust particles is linked to tumorigenesis-associated pathways. A human study showed that miRNA expression (miR-222, miR-21, and miR-146a related with oxidative stress and inflammatory processes) could be a novel mechanism mediating responses to PM (i.e. particulate matter) and its metal components [73].

Chemicals sourced from nutritional sources are also involved in DNA methylation pathways. Folic acid, vitamin $\mathrm{B}_{12}$ and $\mathrm{SAM}$ are key elements in some onecarbon metabolism pathways, which can couple the DNA methylation pathway. DNMTs catalyze the transfer of a methyl group from the methyl donor SAM onto the $5^{\prime}$ position of the cytosine ring residing, in most cases, at the dinucleotide CG sequence. DNMTs use the molecule SAM as their primary source of methyl groups. SAM is manufactured via the folate and methionine pathways, using methionine, choline, folic acid and vitamin $\mathrm{B}_{12}$ ingested in the diet. Studies have shown that DNA methylation correlates positively with folate status in the human body [74]. Diets with high methyl-donating nutrients quickly modify the epigenome, especially in early development. It has been reported [75-78] that feeding female mice with methyl donor diets before and after pregnancy permanently increased DNA methylation in their offspring at the viable yellow agouti $\left(\mathrm{A}^{\mathrm{vy}}\right)$ metastable epiallele; the feeding resulted in brown, healthy offspring. The deficiency of methyl-donating folate or choline during the late foetal or early postnatal developmental stages led to hypomethylation [77]. In adults, a methyl-deficient diet can also result in a decrease of DNA methylation, but this is reversible with a normal diet [79]. However, high maternal dietary intake of methyl donors during gestation was associated with a higher incidence of asthma in mice offspring; decreased transcriptional activity of Runx3, a gene associated with suppression of allergic airway disease, was caused by increased DNA methylation and this was reversible through the administration of a demethylating agent [80]. Aberrant methylation mediated by folate levels has been a suggested risk factor in Alzheimer's disease [81]. Dietary selenium may also influence DNA methylation status and further influence disease predisposition, e.g. cancer [57, 82, 83], by affecting one-carbon metabolism in a different way compared to folate.

\section{Chemical-epigenetic interactions}

Chemical-modified gene activation may involve the ordered cascade of epigenetic events that begin with histone modifications and finalize with alterations in DNA methylation in promoter $\mathrm{CpG}$ islands [3, 84]. A general hypothesis of environmental chemicals as lifelong modulators of DNA hypomethylation is that such xenobiotics, including metals, influences one-carbon metabolism directly or indirectly $[85,86]$. This may explain the population cohort studies that exhibit significant inverse linear relationships between POPs or metals exposures and blood global DNA methylation [87-89]. Patients with atherosclerotic vascular disease often exhibit higher homocysteine and $S$-adenosyl homocysteine (SAHC) and lower genomic DNA methylation status [90, 91], which is directly connected with one-carbon pathways. Indirectly, oxidative stress mechanisms generated by xenobiotics may also involve aberrant epigenetic modification of DNA [85] and histones [92] via the depletion of glutathione (GSH) and changing the ratio of reduced GSH and its oxidized form, GSSG (i.e. GSH disulphide). Oxidative stress may also alter epigenetic modification via mitochondrial dysfunction [93-95]. To be inhibitors, isoflavones, polyphenol, zinc and cadmium may inhibit DNMTs directly and indirectly, and further inhibit methylation of candidate genes [34, 59, 60, 62, 64].

Coinciding with gene-specific aberrant methylation following exposure to endocrine disrupting chemicals, DNMTs were abnormally expressed in some cases [45, 49]. Endocrine disrupting chemicals induced aberrant methylation of oestrogen-regulated genes [43-45]; steroid hormone interacts with chromatin-modifying enzymes by binding the receptors [16] may suggest other pathways by which chemicals alter epigenetic markers, i.e. they may involve the expression of target genes by modifying their epigenetic regulators directly.

\section{Concluding remarks}

In the broadest sense, environmental chemicals appear to alter epigenomic marking and, subsequently gene expression. Particular gene expression profiles can pre-dispose both parental and subsequent generations to an elevated susceptibility to disease [10]. Therefore, these stressors very probably modulate disease susceptibility. The field of environmental epigenomics is still in its infancy; however, a growing body of information is improving our understanding of the interplay between epigenetic alterations, gene expression and environmental stressors. There's an urgent need to study the consequences of exposures at environmentally-relevant levels; this will allow the 
determination of real-world effects and the true relevance of epigenetic mechanisms. It is probable that such epigenetic markers will be used for early molecular diagnosis in those with a predisposition to developing adult diseases due to environmental exposure. For instance, the abnormal methylation of $I g f 2$ and $H 19$ gene expression in sperm of adults may indicate a susceptibility to diabetes in subsequent generations [96]. Furthermore, as the epigenome is modifiable or reversible, this allows for the implementation of strategies to allow disease prevention and targeted treatment. In summary, pollutant-induced epigenetic toxicities turn on or determine latent alterations in gene regulation (Tables S1, S2 and S3 online), such epimutagenic events open up a new horizon in assessment of environmental health.

Acknowledgments This work was supported by Hundred Talent Program of Chinese Academy of Sciences for 2010 on Human Exposure to Environmental Pollutant and Health Effect, National Natural Science Foundation of China (21177123) and Xiamen Science and Technology Fund (3502Z20122003).

\section{References}

1. Peterson CL, Laniel MA (2004) Histones and histone modifications. Curr Biol 14:546-551

2. Portela A, Esteller M (2010) Epigenetic modifications and human disease. Nat Biotechnol 28:1057-1068

3. Lachner M, O'sullivan RJ, Jenuwein T (2003) An epigenetic road map for histone lysine methylation. J Cell Sci 116:2117-2124

4. Nakao M (2001) Epigenetics: interaction of DNA methylation and chromatin. Gene 278:25-31

5. Quina A, Buschbeck M, Di Croce L (2006) Chromatin structure and epigenetics. Biochem Pharmacol 72:1563-1569

6. Perera F, Herbstman J (2011) Prenatal environmental exposures, epigenetics, and disease. Reprod Toxicol 31:363-373

7. Kouzarides T (2007) Chromatin modifications and their function. Cell 128:693-705

8. Mattick JS, Amaral PP, Dinger ME et al (2009) RNA regulation of epigenetic processes. Bioessays 31:51-59

9. Jackson RJ, Standart N (2007) How do microRNAs regulate gene expression? Sci STKE 2007:re1

10. Martin FL (2013) Epigenetic influences in the aetiology of cancers arising from breast and prostate: a hypothesised transgenerational evolution in chromatin accessibility. ISRN Oncol 2013:624794

11. Chueh AC, Northrop EL, Brettingham-Moore KH et al (2009) LINE retrotransposon RNA is an essential structural and functional epigenetic component of a core neocentromeric chromatin. PLoS Genet 5:e1000354

12. Talbert PB, Henikoff S (2006) Spreading of silent chromatin: inaction at a distance. Nat Rev Genet 7:793-803

13. Fischle W, Wang Y, Allis CD (2003) Histone and chromatin cross-talk. Curr Opin Cell Biol 15:172-183

14. Fabbri M, Garzon R, Cimmino A et al (2007) MicroRNA-29 family reverts aberrant methylation in lung cancer by targeting DNA methyltransferases 3A and 3B. Proc Natl Acad Sci USA 104:15805-15810

15. Cedar H, Bergman Y (2009) Linking DNA methylation and histone modification: patterns and paradigms. Nat Rev Genet 10:295-304

16. Mohammad HP, Baylin SB (2010) Linking cell signaling and the epigenetic machinery. Nat Biotechnol 28:1033-1038
17. Martin FL (2007) Epigenomics and disease, 10th anniversary winter meeting of the UK Molecular Epidemiology Group (MEG), The Royal Statistical Society, London, UK, 8 December 2006. Mutagenesis 2007(22):425-427

18. Reamon-Buettner SM, Borlak J (2007) A new paradigm in toxicology and teratology: altering gene activity in the absence of DNA sequence variation. Reproduct Toxicol 24:20-30

19. Szyf M (2007) The dynamic epigenome and its implications in toxicology. Toxicol Sci 100:7-23

20. Szyf M, McGowan P, Meaney MJ (2008) The social environment and the epigenome. Environ Mol Mutagen 49:46-60

21. Baccarelli A, Bollati V (2009) Epigenetics and environmental chemicals. Curr Opin Pediatr 21:243-251

22. Wilhelm-Benartzi CS, Houseman EA, Maccani MA et al (2012) In utero exposures, infant growth, and DNA methylation of repetitive elements and developmentally related genes in human placenta. Environ Health Perspect 120:296-302

23. Cooney CA (2007) Epigenetics-DNA-based mirror of our environment? Dis Markers 23:121-137

24. Anway MD, Cupp AS, Uzumcu M et al (2005) Epigenetic transgenerational actions of endocrine disruptors and male fertility. Science 308:1466-1469

25. Anway MD, Skinner MK (2006) Epigenetic transgenerational actions of endocrine disruptors. Endocrinology 147:s43-s49

26. Groth A, Rocha W, Verreault A et al (2007) Chromatin challenges during DNA replication and repair. Cell 128:721-733

27. Chen H, Ke Q, Kluz T et al (2006) Nickel ions increase histone H3 lysine 9 dimethylation and induce transgene silencing. Mol Cell Biol 26:3728-3737

28. Golebiowski F, Kasprzak KS (2005) Inhibition of core histones acetylation by carcinogenic nickel (II). Mol Cell Biochem 279:133-139

29. Ke Q, Davidson T, Chen H et al (2006) Alterations of histone modifications and transgene silencing by nickel chloride. Carcinogenesis 27:1481-1488

30. Wei YD, Tepperman K, Huang M et al (2004) Chromium inhibits transcription from polycyclic aromatic hydrocarbon-inducible promoters by blocking the release of histone deacetylase and preventing the binding of p300 to chromatin. J Biol Chem 279:4110-4119

31. Kondo K, Takahashi Y, Hirose Y et al (2006) The reduced expression and aberrant methylation of p16INK4a in chromate workers with lung cancer. Lung Cancer 53:295-302

32. Schnekenburger M, Talaska G, Puga A (2007) Chromium crosslinks histone deacetylase 1-DNA methyltransferase 1 complexes to chromatin, inhibiting histone-remodeling marks critical for transcriptional activation. Mol Cell Biol 27:7089-7101

33. Onishchenko N, Karpova N, Sabri F et al (2008) Long-lasting depression-like behavior and epigenetic changes of BDNF gene expression induced by perinatal exposure to methylmercury. J Neurochem 106:1378-1387

34. Poirier LA, Vlasova TI (2002) The prospective role of abnormal methyl metabolism in cadmium toxicity. Environ Health Perspect 110:793-795

35. Takiguchi M, Achanzar WE, Qu W et al (2003) Effects of cadmium on DNA-(cytosine-5) methyltransferase activity and DNA methylation status during cadmium-induced cellular transformation. Exp Cell Res 286:355-365

36. Belinsky SA, Klinge DM, Liechty KC et al (2004) Plutonium targets the p16 gene for inactivation by promoter hypermethylation in human lung adenocarcinoma. Carcinogenesis 25:1063-1067

37. Reichard JF, Schnekenburger M, Puga A (2007) Long term lowdose arsenic exposure induces loss of DNA methylation. Biochem Biophys Res Commun 352:188-192

38. Weaver ICG, Champagne FA, Brown SE et al (2005) Reversal of maternal programming of stress responses in adult offspring 
through methyl supplementation: altering epigenetic marking later in life. J Neurosci 25:11054

39. Chanda S, Dasgupta UB, GuhaMazumder D et al (2006) DNA hypermethylation of promoter of gene p53 and p16 in arsenicexposed people with and without malignancy. Toxicol Sci 89:431-437

40. Pilsner JR, Liu X, Ahsan H et al (2007) Genomic methylation of peripheral blood leukocyte DNA: influences of arsenic and folate in Bangladeshi adults. Am J Clin Nutr 86:1179-1186

41. Crews D, Gore AC, Hsu TS et al (2007) Transgenerational epigenetic imprints on mate preference. Proc Natl Acad Sci USA 104:5942-5946

42. Schüssel S (2008) Altered microRNA expression in response to vinclozolin exposure. Dissertation, Brown University, Rhode Island

43. Li S, Hansman R, Newbold R et al (2003) Neonatal diethylstilbestrol exposure induces persistent elevation of c-fos expression and hypomethylation in its exon-4 in mouse uterus. Mol Carcinogen 38:78-84

44. Newbold RR, Padilla-Banks E, Jefferson WN (2006) Adverse effects of the model environmental estrogen diethylstilbestrol are transmitted to subsequent generations. Endocrinology 147:s11-s17

45. Sato K, Fukata H, Kogo Y et al (2006) Neonatal exposure to diethylstilbestrol alters the expression of DNA methyltransferases and methylation of genomic DNA in the epididymis of mice. Endocr J 53:337

46. Ho SM, Tang WY, Belmonte de Frausto J et al (2006) Developmental exposure to estradiol and bisphenol A increases susceptibility to prostate carcinogenesis and epigenetically regulates phosphodiesterase type 4 variant 4 . Cancer Res 66:5624-5632

47. Dolinoy DC, Huang D, Jirtle RL (2007) Maternal nutrient supplementation counteracts bisphenol A-induced DNA hypomethylation in early development. Proc Natl Acad Sci USA 104:13056-13061

48. Paul S, Kim S, Park $\mathrm{H}$ et al (2009) Alteration in miRNA expression profiling with response to nonylphenol in human cell lines. Mol Cell Toxicol 5:67-74

49. Wu Q, Ohsako S, Ishimura R et al (2004) Exposure of mouse preimplantation embryos to 2,3,7,8-tetrachlorodibenzo- $p$-dioxin (TCDD) alters the methylation status of imprinted genes H19 and Igf2. Biol Reprod 70:1790-1797

50. Kang SC, Lee BM (2005) DNA methylation of estrogen receptor $\alpha$ gene by phthalates. J Toxicol Environ Health A 68:1995-2003

51. McLachlan JA, Simpson E, Martin M (2006) Endocrine disrupters and female reproductive health. Best Pract Res Clin Endocrinol Metab 20:63-75

52. Tao L, Wang W, Li L et al (2005) DNA hypomethylation induced by drinking water disinfection by-products in mouse and rat kidney. Toxicol Sci 87:344-352

53. Wu S, Zhu J, Li Y et al (2010) Dynamic effect of di-2-(ethylhexyl) phthalate on testicular toxicity: epigenetic changes and their impact on gene expression. Int J Toxicol 29:193-200

54. Rahman I, Gilmour PS, Jimenez LA et al (2002) Oxidative stress and TNF- $\alpha$ induce histone acetylation and NF- $\mathrm{KB} / \mathrm{AP}-1$ activation in alveolar epithelial cells: potential mechanism in gene transcription in lung inflammation. Mol Cell Biochem 234:239-248

55. Esteller M (2005) DNA methylation and cancer therapy: new developments and expectations. Curr Opin Oncol 17:55-60

56. Davis CD, Uthus EO (2003) Dietary folate and selenium affect dimethylhydrazine-induced aberrant crypt formation, global DNA methylation and one-carbon metabolism in rats. J Nutr 133:2907-2914

57. Ecke I, Petry F, Rosenberger A et al (2009) Antitumor effects of a combined 5-aza-2' deoxycytidine and valproic acid treatment on rhabdomyosarcoma and medulloblastoma in Ptch mutant mice. Cancer Res 69:887-895

58. Pogribny IP, Tryndyak VP, Boyko A et al (2007) Induction of microRNAome deregulation in rat liver by long-term tamoxifen exposure. Mutat Res 619:30-37
59. Day JK, Bauer AM, desBordes C et al (2002) Genistein alters methylation patterns in mice. J Nutr 132:2419S-2423S

60. Dolinoy DC, Weidman JR, Waterland RA et al (2006) Maternal genistein alters coat color and protects Avy mouse offspring from obesity by modifying the fetal epigenome. Environ Health Perspect 114:567-572

61. Fang MZ, Wang Y, Ai N et al (2003) Tea polyphenol (-)-epigallocatechin-3-gallate inhibits DNA methyltransferase and reactivates methylation-silenced genes in cancer cell lines. Cancer Res 63:7563-7570

62. Lee WJ, Shim JY, Zhu BT (2005) Mechanisms for the inhibition of DNA methyltransferases by tea catechins and bioflavonoids. Mol Pharmacol 68:1018-1030

63. Yuasa Y, Nagasaki H, Akiyama Y et al (2009) DNA methylation status is inversely correlated with green tea intake and physical activity in gastric cancer patients. Int J Cancer 124:2677-2682

64. Hong T, Nakagawa T, Pan WJ et al (2004) Isoflavones stimulate estrogen receptor-mediated core histone acetylation. Biochem Biophys Res Commun 317:259-264

65. Liu H, Zhou Y, Boggs S et al (2007) Cigarette smoke induces demethylation of prometastatic oncogene synuclein- $\gamma$ in lung cancer cells by downregulation of DNMT3B. Oncogene 26:5900-5910

66. Perera F, Tang W, Herbstman J et al (2009) Relation of DNA methylation of $5^{\prime}-\mathrm{CpG}$ island of ACSL3 to transplacental exposure to airborne polycyclic aromatic hydrocarbons and childhood asthma. PLoS One 4:e4488

67. Pulling LC, Vuillemenot BR, Hutt JA et al (2004) Aberrant promoter hypermethylation of the death-associated protein kinase gene is early and frequent in murine lung tumors induced by cigarette smoke and tobacco carcinogens. Cancer Res 64:3844-3848

68. Izzotti A, Calin GA, Arrigo P et al (2009) Downregulation of microRNA expression in the lungs of rats exposed to cigarette smoke. FASEB J 23:806-812

69. Ouko LA, Shantikumar K, Knezovich J et al (2009) Effect of alcohol consumption on $\mathrm{CpG}$ methylation in the differentially methylated regions of $\mathrm{H} 19$ and IG-DMR in Male Gametes: implications for fetal alcohol spectrum disorders. Alcohol Clin Exp Res 33:1615-1627

70. Impey S (2007) A histone deacetylase regulates addiction. Neuron $56: 415-417$

71. Tarantini L, Bonzini M, Apostoli P et al (2009) Effects of particulate matter on genomic DNA methylation content and iNOS promoter methylation. Environ Health Perspect 117:217-222

72. Jardim MJ, Fry RC, Jaspers I et al (2009) Disruption of microRNA expression in human airway cells by diesel exhaust particles is linked to tumorigenesis-associated pathways. Environ Health Perspect 117:1745-1751

73. Bollati V, Marinelli B, Apostoli P et al (2010) Exposure to metalrich particulate matter modifies the expression of candidate microRNAs in peripheral blood leukocytes. Environ Health Perspect 118:763-768

74. Friso S, Choi SW, Girelli D et al (2002) A common mutation in the 5,10-methylenetetrahydrofolate reductase gene affects genomic DNA methylation through an interaction with folate status. Proc Natl Acad Sci USA 99:5606-5611

75. Cooney CA, Dave AA, Wolff GL (2002) Maternal methyl supplements in mice affect epigenetic variation and DNA methylation of offspring. J Nutr 132:2393S-2400S

76. Cropley JE, Suter CM, Beckman KB et al (2006) Germ-line epigenetic modification of the murine Avy allele by nutritional supplementation. Proc Natl Acad Sci USA 103:17308-17312

77. Waterland RA, Jirtle RL (2003) Transposable elements: targets for early nutritional effects on epigenetic gene regulation. Mol Cell Biol 23:5293-5300

78. Waterland RA, Dolinoy DC, Lin JR et al (2006) Maternal methyl supplements increase offspring DNA methylation at Axin Fused. Genesis 44:401-406 
79. Ingrosso D, Cimmino A, Perna AF et al (2003) Folate treatment and unbalanced methylation and changes of allelic expression induced by hyperhomocysteinaemia in patients with uraemia. Lancet 361:1693-1699

80. Hollingsworth JW, Maruoka S, Boon K et al (2008) In utero supplementation with methyl donors enhances allergic airway disease in mice. J Clin Invest 118:3462-3469

81. Zawia NH, Lahiri DK, Cardozo-Pelaez F (2009) Epigenetics, oxidative stress, and Alzheimer disease. Free Radic Biol Med 46:1241-1249

82. Arasaradnam R, Commane D, Bradburn D et al (2008) A review of dietary factors and its influence on DNA methylation in colorectal carcinogenesis. Epigenetics 3:193-198

83. Xiang N, Zhao R, Song G et al (2008) Selenite reactivates silenced genes by modifying DNA methylation and histones in prostate cancer cells. Carcinogenesis 29:2175-2181

84. Teneng I, Montoya-Durango DE, Quertermous JL et al (2011) Reactivation of L1 retrotransposon by benzo(a)pyrene involves complex genetic and epigenetic regulation. Epigenetics 6:355-367

85. Lee DH, Jacobs DR Jr, Porta M (2009) Hypothesis: a unifying mechanism for nutrition and chemicals as lifelong modulators of DNA hypomethylation. Environ Health Perspect 117:1799-1802

86. Foley DL, Craig JM, Morley R et al (2009) Prospects for epigenetic epidemiology. Am J Epidemiol 169:389-400

87. Kim KY, Kim DS, Lee SK et al (2010) Association of low-dose exposure to persistent organic pollutants with global DNA hypomethylation in healthy Koreans. Environ Health Perspect 118:370-374
88. Rusiecki JA, Baccarelli A, Bollati V et al (2008) Global DNA hypomethylation is associated with high serum-persistent organic pollutants in Greenlandic Inuit. Environ Health Perspect 116:1547-1552

89. Wright RO, Schwartz J, Wright RJ et al (2010) Biomarkers of lead exposure and DNA methylation within retrotransposons. Environ Health Perspect 118:790-795

90. Castro R, Rivera I, Struys EA et al (2003) Increased homocysteine and $S$-adenosylhomocysteine concentrations and DNA hypomethylation in vascular disease. Clin Chem 49:1292-1296

91. Krause B, Sobrevia L, Casanello P (2009) Epigenetics: new concepts of old phenomena in vascular physiology. Curr Vasc Pharmacol 7:513-520

92. Rahman I, Marwick J, Kirkham P (2004) Redox modulation of chromatin remodeling: impact on histone acetylation and deacetylation, NF-[kappa] B and pro-inflammatory gene expression. Biochem Pharmacol 68:1255-1267

93. Naviaux RK (2008) Mitochondrial control of epigenetics. Cancer Biol Ther 7:1191-1193

94. Smiraglia DJ, Kulawiec M, Bistulfi GL et al (2008) A novel role for mitochondria in regulating epigenetic modification in the nucleus. Cancer Biol Ther 7:1182-1190

95. Wallace DC, Fan W (2010) Energetics, epigenetics, mitochondrial genetics. Mitochondrion 10:12-31

96. Ding GL, Wang FF, Shu J et al (2012) Transgenerational glucose intolerance with Igf2/H19 epigenetic alterations in mouse islet induced by intrauterine hyperglycemia. Diabetes $61: 1133-1142$ 